\title{
Lateral strength and ductility of reinforced concrete columns strengthened with NSM FRP rebars and FRP jacket
}

\author{
Ehsan Noroozieh ${ }^{1} \cdot$ Ali Mansouri $^{1}$ (i)
}

Received: 20 December 2018 / Accepted: 22 April 2019 / Published online: 3 May 2019

(c) The Author(s) 2019

\begin{abstract}
Fiber-reinforced polymer (FRP) wrapping of reinforced concrete (RC) columns is an effective way to improve their shear capacity and ductility and prevent buckling in their longitudinal reinforcements. Another strengthening method called the near surface mounted (NSM) reinforcement has been proven effective in improving the flexural strength of RC columns. In this research, the strengthening of RC columns with the combined use of NSM rebars and FRP jacket was studied using a finite element modeling approach. After validating the numerical models with the existing experimental data, a comprehensive parametric study was performed to determine the effect of axial load, implementing the FRP confinement around the base or over the entire height of the column, the number of plies of FRP jacket, the type of jacket fiber, the ratio of NSM reinforcement, and the compressive strength of the concrete on the behavior of the strengthened RC columns. The results show that the optimum number of plies of jacket for reaching a desirable level of ductility can be determined by setting the maximum compressive strain in the confined concrete, $\varepsilon_{\mathrm{ccu}}$, to 0.008 . Increasing the ratio of NSM reinforcement from $0.16 \%$ of the total cross-sectional area to $1 \%$ led to approximately $28 \%$ increase in the lateral strength and $50 \%$ decrease in the ductility factor.
\end{abstract}

Keywords Reinforced concrete column $\cdot$ Near surface mounted (NSM) $\cdot$ Fiber-reinforced polymer (FRP) jacket $\cdot$ Flexural strengthening $\cdot$ Seismic performance

\section{Introduction}

Fiber-reinforced polymer (FRP) wrapping of reinforced concrete $(\mathrm{RC})$ columns can improve their ductility and energy dissipation capacity and prevent buckling in their longitudinal reinforcements. However, FRP wrapping is not much effective against eccentric loads and does not significantly contribute to the flexural strength of RC columns. Hence, alternative methods are needed to increase the flexural strength of these members (El-Maaddawy and El-Dieb 2011; Kabir and Mansouri 2008; Yao and Wu 2016). The near surface mounted (NSM) reinforcement is a new method for flexural strengthening of RC columns. This method involves creating a series of grooves in the concrete cover and inserting reinforcing bars or strips inside so as to improve the flexural strength of the column. This method does not require any surface preparation and is faster to implement than other

Ali Mansouri

a.mansouri@qiet.ac.ir

1 Department of Civil Engineering, Quchan University of Technology, Quchan, Iran external reinforcement methods (Perrone et al. 2009; Sarafraz and Danesh 2012). The NSM method is also very effective in improving the seismic performance of RC columns against cyclic loads (El-Maaddawy and El-Dieb 2011). The drawbacks of this method include the inability to improve the energy dissipation of RC columns and the fact that NSM rebars tend to buckle and get dislodged from concrete cover (Perrone et al. 2009).

To overcome the limitations of FRP wrapping and NSM techniques, researchers have investigated the viability of various combinations of these methods in strengthening the RC columns. Laboratory studies of Bournas and Triantafillou (2009) on the RC columns strengthened with NSM and FRP jacket showed that the combined use of these methods improves the ductility and flexural strength of columns. In another laboratory research, Perrone et al. (2009) studied the behavior of square cross-sectional RC columns strengthened with NSM bars and CFRP jacket under constant axial load and cyclic lateral load. This study reported that the use of both methods together led to $67 \%$ increase in the bearing capacity of non-damaged columns and $46 \%$ increase in that of damaged columns. 
El-Maaddawy and El-Dieb (2011) investigated the effect of the NSM method and external confinement on the RC columns under axial load and biaxial bending. After developing an analytical model for predicting the capacity, they showed that the confinement system alone cannot effectively improve the flexural strength, but the combined use of NSM and confinement methods improves the load-bearing capacity and the lateral deformation capacity of columns, even under highly eccentric loads. Sarafraz and Danesh (2012) tested seven RC columns strengthened with NSM rebars and FRP jacket under constant compressive axial load and cyclic lateral load. This study found that the use of FRP jacket alone improves the axial strength, shear strength, and stiffness of the member, but not its flexural capacity. It was also reported that the use of NSM rebars increases the lateral load-bearing capacity and flexural strength of RC columns, and the greater the ratio of NSM reinforcement, the greater is the increase in flexural strength. They concluded that the simultaneous use of both methods is the best approach for improving the flexural capacity and ductility of RC columns, as FRP wrapping limits the instability of NSM rebars and prevents cracking in the grout when rebars are subjected to tensile loads. In a research conducted by Moodi et al. (2016), they tested five RC columns strengthened with the NSM method and CFRP confinement system and studied the effect of the size of concrete cover on the load-bearing and energy dissipation results. This study reported that as the size of the concrete cover increased from 20 to $40 \mathrm{~mm}$, the load-bearing capacity and the energy dissipation capacity of NSM-strengthened specimens decreased by $10 \%$ and $18 \%$, respectively; but in the specimens strengthened with both methods, these reductions amounted to $25 \%$ and $33 \%$, respectively. Fahmy and Wu (2016) studied the strengthening of three RC columns with inadequate lap-splice length by the use of NSM basalt fiber-reinforced polymer (BFRP) rebars and BFRP jacket applied to the plastic hinge formation region. They also considered the effect of the texture of the BFRP rebar (smooth/rough) on the results. According to the results of this study, the texture of the FRP rebar has a significant impact on the performance of the strengthened RC columns. They also reported that the specimen strengthened with rough FRP exhibited more ductile behavior with less residual drift. In a study conducted by Jiang et al. (2016), the tests carried out on four circular bridge columns, which had sustained earthquake-induced damage and then strengthened with BFRP jacket and NSM BRBF rebars, showed that this method is indeed a quick and convenient way to improve the flexural strength, stiffness, and drift capacity of the columns damaged by earthquakes. They also reported that the confinement of the column with BFRP jacket limits the buckling of NSM rebars and increases the ductility of the column. Seifi et al. (2018) studied the behavior of RC columns strengthened with NSM rebars and CFRP jacket through a series of tests conducted on nine specimens. This study found that the specimens strengthened with NSM steel rebars had a higher flexural strength, ductility, and energy dissipation than those strengthened with NSM GFRP rebars. The laboratory tests and modeling conducted by Seifi et al. (2017) also showed that implementing this method of strengthening on vulnerable RC frames allows us to achieve a strong column-weak beam design and prevent the soft story mechanism.

Recent studies on the subject, although still few in numbers, have dominantly demonstrated the desirable performance of RC columns strengthened with the aforementioned methods. However, the actual use of these methods to strengthen RC columns requires further insight into the behavior of the resulting member and the effect of different parameters on its performance. In the present work, the behavior of RC columns strengthened with the aforementioned methods is studied through finite element modeling and analysis. After validating the numerical model with the existing experimental data, a series of parametric analyses are conducted to investigate the effect of axial load, confinement of the column base or the entire column, the number of plies of the FRP jacket, the type of jacket fiber, the ratio of NSM reinforcement, and the compressive strength of the concrete on the behavior of the strengthened RC column. In the course of each analysis, we also provide some suggestions for better strengthening of columns via this method.

\section{Reference experimental data}

The numerical model used in this study was validated using the experimental data provided by Sarafraz and Danesh (2012). In that study, RC column specimens were tested under constant axial and cyclic lateral loads. A concrete block was fitted above the specimens to facilitate the application of axial and lateral loads, and another concrete block was created on the laboratory floor to serve as the rigid foundation. The specimens used in that study were $200 \times 200 \times 1000 \mathrm{~mm}$ in size. The specimen strengthened with NSM rebars and CFRP jacket was used to validate the model developed in the finite element software Abaqus (2007). Figure 1 shows a schematic diagram of the specimen. This specimen was equivalent to half of a column in a moment frame (from the column base to the middle of its height). The specimen was made of concrete with a compressive strength of $24.1 \mathrm{MPa}$. The mean yield strength of longitudinal and transverse reinforcements was $410 \mathrm{MPa}$ and $389 \mathrm{MPa}$, respectively. The CFRP sheet used in the jacket had a tensile strength of $3800 \mathrm{MPa}$, a modulus of elasticity of $240 \mathrm{GPa}$, and a thickness of $0.176 \mathrm{~mm}$. The NSM rebars used in this experiment had a diameter of $10 \mathrm{~mm}$, a tensile strength of $760 \mathrm{MPa}$, and a modulus of elasticity of $40.8 \mathrm{GPa}$. The 


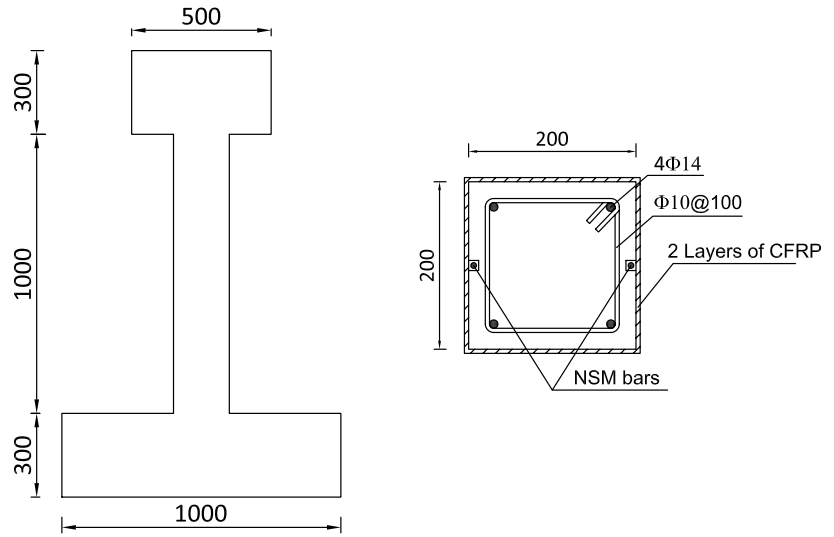

Fig. 1 Reference laboratory specimen used for the validation (all dimensions are in mm; Sarafraz and Danesh 2012)

epoxy adhesive used in the experiment had a tensile strength of $27.6 \mathrm{MPa}$ and a modulus of elasticity of $3 \mathrm{GPa}$.

\section{Modeling of materials}

Since specimens are supposed to be made of various materials, each capable of exhibiting distinctive plasticity and damage behavior under lateral load, the use of suitable constitutive models capable of emulating the actual behavior of materials is of particular importance for the accuracy of the results. The constitutive models used in our models are described below.

\section{Concrete}

Considering the presence of FRP jacket in numerical models, the constitutive model to be used for concrete should be able to account for the effect of confining pressure of the FRP jacket on the stress-strain curve of the concrete. Given the ability of the concrete damaged plasticity model in this regard (Jamatia et al. 2013), this model was used to simulate the behavior of concrete in the plastic region. The constitutive model proposed by Kent and Park (1971) was used to determine the stress-strain relationship. The compressive stress-strain curve of the concrete based on this model is illustrated in Fig. 2. The ascending part of this stress-strain curve is expressed by the following relationship:

$\sigma_{\mathrm{c}}=f_{\mathrm{c}}^{\prime}\left[2\left(\frac{\varepsilon_{\mathrm{c}}}{\varepsilon_{\mathrm{c}}^{\prime}}\right)-\left(\frac{\varepsilon_{\mathrm{c}}}{\varepsilon_{\mathrm{c}}^{\prime}}\right)^{2}\right]$,

where $\sigma_{\mathrm{c}}$ and $\varepsilon_{\mathrm{c}}$ are the compressive stress and strain, and $f_{\mathrm{c}}^{\prime}$ and $\varepsilon_{\mathrm{c}}^{\prime}$ are the compressive strength of the cylindrical concrete sample and its corresponding strain. Park and Pauli (1975) have recommended the value of 0.002 for $\varepsilon_{\mathrm{c}}^{\prime}$. The descending part of the above curve (after the peak) is a

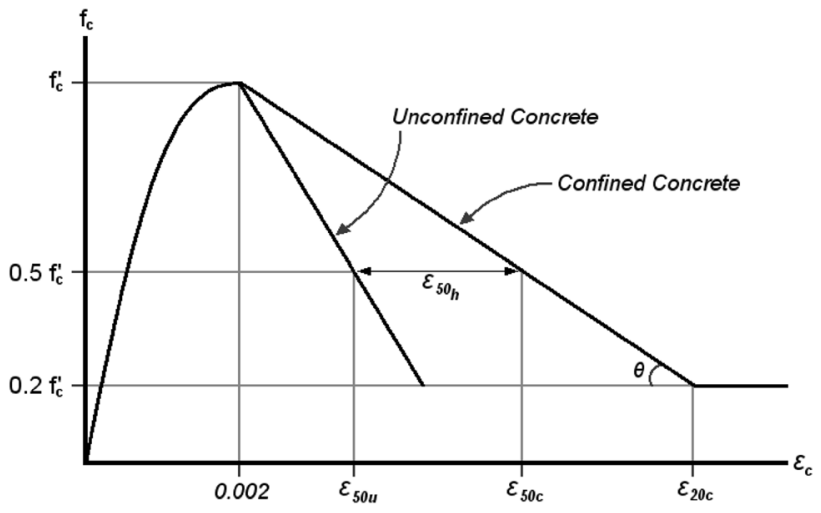

Fig. 2 Compressive stress-strain curve of concrete based on the model of Kent and Park (1971)

straight line with a slope that is a function of the compressive strength of the concrete:

$\sigma_{\mathrm{c}}=f_{\mathrm{c}}^{\prime}\left[1-Z\left(\varepsilon_{\mathrm{c}}-\varepsilon_{\mathrm{c}}^{\prime}\right)\right]$,

where

$Z=\frac{0.5}{\varepsilon_{50 \mathrm{u}}-\varepsilon_{\mathrm{c}}^{\prime}}$.

In this equation, $\varepsilon_{50 \mathrm{u}}$ is the strain corresponding to $50 \%$ reduction in compressive strength of the concrete, which can be obtained from the following equation:

$\varepsilon_{50 \mathrm{u}}=\frac{3+0.29 f_{\mathrm{c}}^{\prime}}{145 f_{\mathrm{c}}^{\prime}-1000}\left(f_{\mathrm{c}}^{\prime}\right.$ in MPa $)$.

In the course of modeling the concrete, the following relationships were used to convert the nominal stress and strain values into their true counterparts:

$\varepsilon=\ln \left(1+\varepsilon_{\text {nom }}\right)$,

$\sigma=\sigma_{\text {nom }}\left(1+\varepsilon_{\text {nom }}\right)$.

In these relationships, $\sigma_{\text {nom }}$ and $\varepsilon_{\text {nom }}$ denote the nominal stress and strain, and $\sigma$ and $\varepsilon$ are the true stress and strain values, respectively.

The concrete damaged plasticity model combines the nonassociated multi-hardening plasticity with scalar (isotropic) damaged elasticity. This model assumes two mechanisms of failure in concrete: tensile cracking and compressive crushing.

Under tensile stress, the tension-strain relationship is considered to be linear until the failure stress $\sigma_{\mathrm{t} 0}$ (Fig. 3a), which corresponds to the initiation of micro-cracking in concrete. After that point, further expansion of microcracks leads to a decrease in the tensile strength of the 

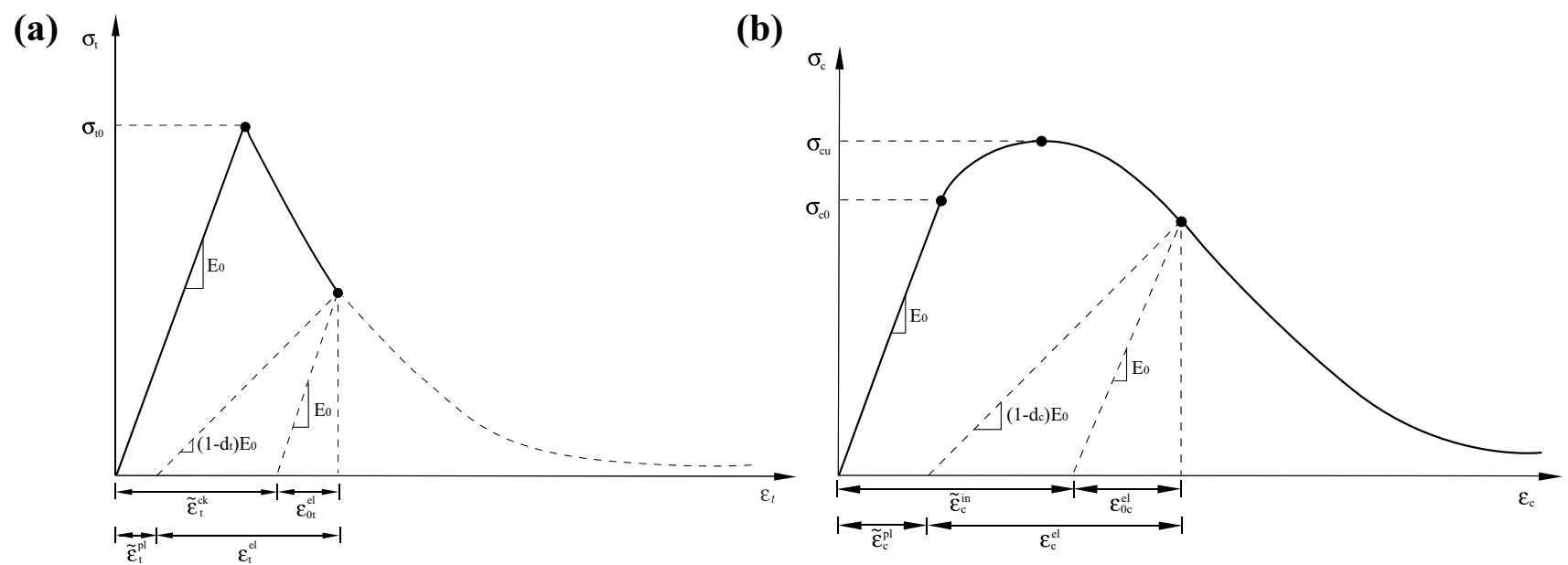

Fig. 3 Effect of damage on the stress-strain curve of concrete: a under tensile stress; $\mathbf{b}$ under compressive stress (Abaqus 2007)

concrete. Under compressive stress, the response is linear until the initial yield point $\sigma_{\mathrm{y} 0}$, after which we have a nonlinear region, where stress increases up to a maximum of $\sigma_{\mathrm{cu}}$, and then a descending curve, where the expansion of damage results in a steady decrease in the strength of the concrete (Fig. 3b).

The damage variables $d_{\mathrm{t}}$ and $d_{\mathrm{c}}$ were used to model the effect of the development of damage on the behavior of concrete under tensile and compressive stresses, respectively. In fact, these parameters control the slope of the descending branch of the stress-strain curve. The stress-strain relations after the initiation of damage under tensile and compressive stresses are expressed by Eqs. (7) and (8), respectively.

$\sigma_{\mathrm{t}}=\left(1-d_{\mathrm{t}}\right) E_{0}\left(\varepsilon_{\mathrm{t}}-\tilde{\varepsilon}_{\mathrm{t}}^{\mathrm{pl}}\right)$,

$\sigma_{\mathrm{c}}=\left(1-d_{\mathrm{c}}\right) E_{0}\left(\varepsilon_{\mathrm{c}}-\tilde{\varepsilon}_{\mathrm{c}}^{\mathrm{pl}}\right)$.

In these equations, $E_{0}$ is the initial stiffness of the material (in the undamaged state), $\varepsilon_{\mathrm{t}}$ and $\varepsilon_{\mathrm{c}}$ are the tensile and compressive strains, and $\sigma_{\mathrm{t}}$ and $\sigma_{\mathrm{c}}$ are the tensile and compressive stresses. The parameters $\tilde{\varepsilon}_{\mathrm{t}}^{\mathrm{pl}}$ and $\tilde{\varepsilon}_{\mathrm{c}}^{\mathrm{pl}}$ denote the equivalent plastic strain in the tensile and compressive regimes and are given by the following equations:

$\tilde{\varepsilon}_{\mathrm{t}}^{\mathrm{pl}}=\tilde{\varepsilon}_{\mathrm{t}}^{\mathrm{ck}}-\frac{d_{\mathrm{t}}}{\left(1-d_{\mathrm{t}}\right)} \frac{\sigma_{\mathrm{t}}}{E_{0}}$,

$\tilde{\varepsilon}_{\mathrm{c}}^{\mathrm{pl}}=\tilde{\varepsilon}_{\mathrm{c}}^{\mathrm{in}}-\frac{d_{\mathrm{c}}}{\left(1-d_{\mathrm{c}}\right)} \frac{\sigma_{\mathrm{c}}}{E_{0}}$.

In the above equations, $\tilde{\varepsilon}_{\mathrm{t}}^{\mathrm{ck}}$ is the cracking strain displayed in Fig. 3a and $\tilde{\varepsilon}_{\mathrm{c}}^{\text {in }}$ is the inelastic strain displayed in Fig. $3 \mathrm{~b}$.

\section{Steel}

The finite element modeling of steel reinforcement was carried out based on the Mises yield surface, which has been defined as follows:

$f=\sqrt{\frac{3}{2}(S-\alpha):(S-\alpha)}-\sigma^{0}$,

where $\sigma^{0}$ is the yield stress, $S$ is the deviatoric stress tensor, and $\boldsymbol{\alpha}$ is the deviatoric part of the back stress tensor.

The steel material was modeled using the linear kinematic hardening model and associated plastic flow. The kinematic hardening model is a good choice for modeling the behavior of most metals under cyclic loads. In this model, an increase in the equivalent plastic strain leads to the translation of the yield surface in the stress space as a result of changes in the back stress $\alpha$. This model utilizes the following evolution law:

$\dot{\alpha}=C \frac{1}{\sigma^{0}}(\sigma-\alpha) \dot{\bar{\varepsilon}}^{\mathrm{pl}}$,

where $\sigma$ is the stress tensor, $\dot{\bar{\varepsilon}}^{p l}$ is the equivalent plastic strain rate, and $C$ is the kinematic hardening modulus.

\section{FRP jacket, NSM rebars, and adhesive}

The FRP jacket was modeled as a laminar orthotropic material. The elastic properties of the materials were defined as listed in Table 1, where $E_{1}$ and $E_{2}$ are the moduli of elasticity in the directions parallel and perpendicular to the fiber, $v$ is the Poisson's ratio, and $G$ is the shear modulus. Since FRP is an elastic-brittle material, damage in this material can initiate without a nonlinear deformation. Damage was simulated 
Table 1 Mechanical properties of the composites used in the jacket (Hahn and Tsai 1980)

\begin{tabular}{lllll}
\hline CFRP & & & GFRP & \\
\cline { 1 - 2 } Stress analysis & Failure analysis & & Stress analysis & Failure analysis \\
\hline$E_{1}=181 \mathrm{GPa}$ & $X_{\mathrm{T}}=1500 \mathrm{MPa}$ & & $E_{1}=38.6 \mathrm{GPa}$ & $X_{\mathrm{T}}=1062 \mathrm{MPa}$ \\
$E_{2}=10.3 \mathrm{GPa}$ & $X_{\mathrm{C}}=1500 \mathrm{MPa}$ & $E_{2}=8.27 \mathrm{GPa}$ & $X_{\mathrm{C}}=610 \mathrm{MPa}$ \\
$\nu_{12}=0.28$ & $Y_{\mathrm{T}}=40 \mathrm{MPa}$ & & $v_{12}=0.26$ & $Y_{\mathrm{T}}=31 \mathrm{MPa}$ \\
$G_{12}=7.17 \mathrm{GPa}$ & $Y_{\mathrm{C}}=246 \mathrm{MPa}$ & & $G_{12}=4.14 \mathrm{GPa}$ & $Y_{\mathrm{C}}=118 \mathrm{MPa}$ \\
$G_{13}=7.17 \mathrm{GPa}$ & $S=68 \mathrm{MPa}$ & & $G_{13}=4.14 \mathrm{GPa}$ & $S=72 \mathrm{MPa}$ \\
$G_{23}=6.30 \mathrm{GPa}$ & & & $G_{23}=3.10 \mathrm{GPa}$ & \\
\hline
\end{tabular}

based on the Hashin model (1980), which is available in the Abaqus software. The strength of the composite materials was set to the values listed in Table 1 , where $X_{\mathrm{T}}$ and $X_{\mathrm{C}}$ are the tensile and compressive strength of the materials in the direction parallel to the fiber orientation, $Y_{\mathrm{T}}$ and $Y_{\mathrm{C}}$ are the tensile and compressive strength of materials in the direction perpendicular to the fiber orientation, and $S$ is the in-plane shear strength. Hashin model includes four different damage initiation criteria: (i) fiber tension, (ii) fiber compression, (iii) matrix tension, and (iv) matrix compression. In this model, damage development has been formulated based on the energy dissipated in the damage process. To model the brittle failure, the failure energy of the numerical model was set to a low value. Given the absence of any observation suggesting the failure of the adhesive in the experiments, the adhesive was modeled as an isotropic material with linear elastic behavior. FRP rebar was assumed to have a linear elastic behavior with brittle failure at the moment of reaching the tensile strength.

\section{Numerical modeling and validation}

Numerical modeling and analysis were carried out using the finite element software Abaqus. Concrete and adhesive were modeled using the cubic element C3D8R with eight nodes and three degrees of freedom per node and reduced integration. Longitudinal and transverse reinforcements and FRP rebars were modeled using the linear truss element T3D2, and FRP jacket was modeled using the shell element S4R with four nodes and reduced integration. The components of the numerical model are shown in Fig. 4. After conducting a sensitivity analysis on the mesh size, the threshold over which further downscaling of the mesh would make no significant improvement in the results was chosen as the mesh size to be used in modeling.

In emulation of the reference experimental data, a constant axial force of $200 \mathrm{KN}$ was applied to the top of the column, and lateral cyclic displacement was applied to the upper block of the column using the displacement-controlled approach. The amplitudes of imposed displacements were multiples of $5 \mathrm{~mm}$. Similar to the reference laboratory experiment, the axial load was applied before the lateral displacement, and the bottom block was assumed to be clamped and given no degree of freedom.

The interactions between adhesive and concrete and between concrete and jacket were modeled using the tie constraint. With this constraint, the members remain completely attached together and stay tied and act continuously throughout the analysis. The boundary of concrete with steel reinforcement and with FRP rebars was modeled using the embedded region constraint. Using this constraint, a region of the model will be embedded in another region in a way that they will both have the same degrees of freedom.

In the numerical model, flexural cracking and crushing in the concrete was observed at the lower section of the column, which indicates the formation of the flexural plastic hinge in this region. This is a common failure mode of $\mathrm{RC}$ columns that was also observed in other experimental programs (Mansouri et al. 2014, 2018). In Fig. 5, the compressive damage in the concrete of the numerical model is displayed alongside the real damage observed in the corresponding laboratory experiment (Sarafraz and Danesh 2012).

The evaluation of the stress in the column's steel reinforcements also points to the formation of the flexural
Fig. 4 Components of the numerical model: a concrete parts; b steel reinforcements; c NSM FRP bars; $\mathbf{d}$ epoxy adhesive; e FRP jacket

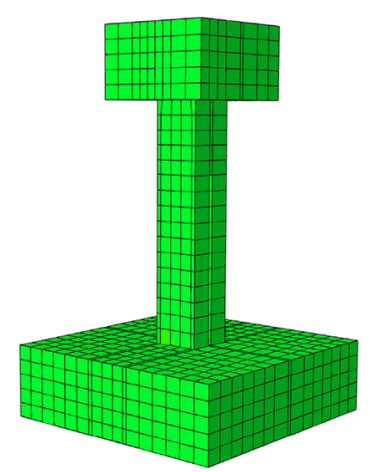

(a)

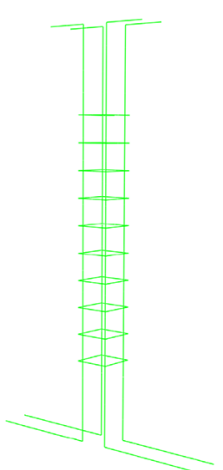

(b)

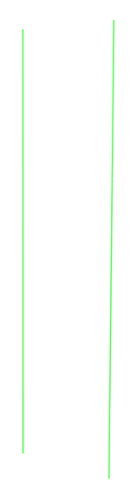

(c)

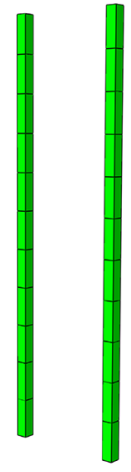

(d)

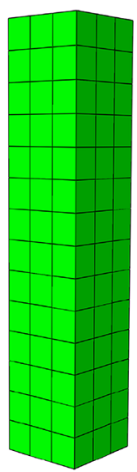

(e) 
Fig. 5 Comparison of compressive damage in the concrete in the simulated specimen and in the corresponding laboratory specimen (Sarafraz 2012; Sarafraz and Danesh 2012)
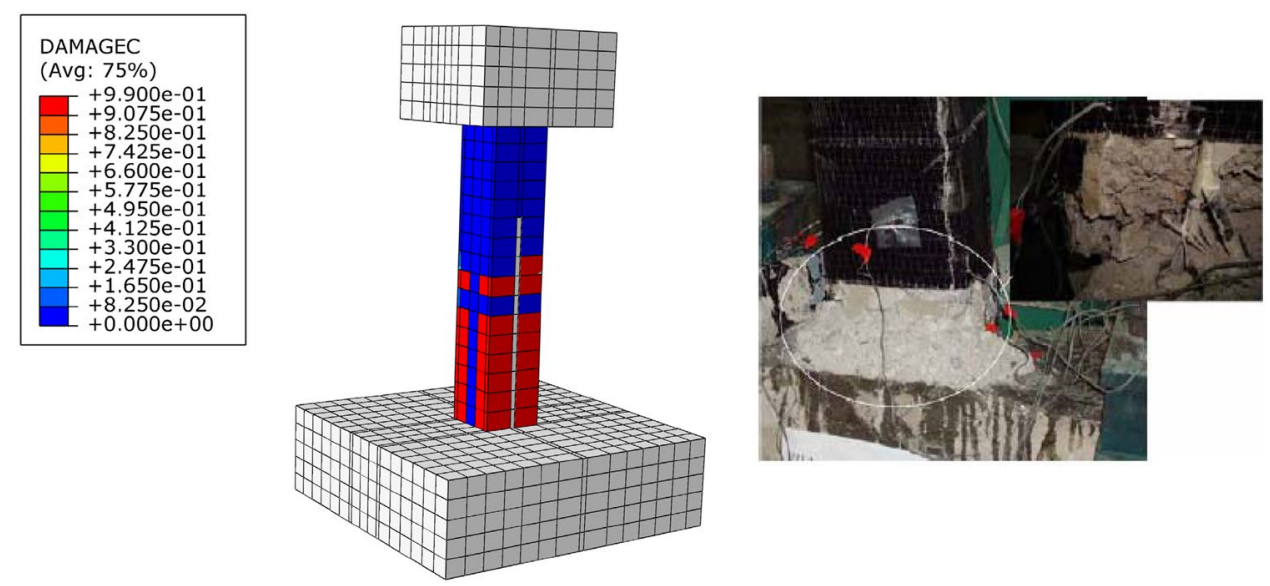

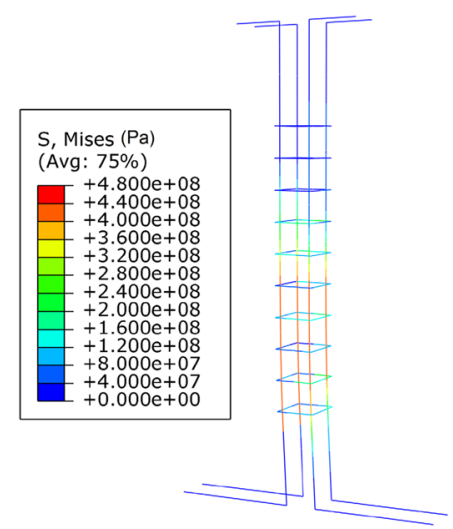

(a)
Fig. 6 Stress contours in the components of the numerical model at the end of lateral loading: a Mises stress in longitudinal and transverse rebars; $\mathbf{b}$ longitudinal stress in the FRP rebars; $\mathbf{c}$ transverse stress in the FRP jacket plastic hinge at the base of the specimen. A high degree of similarity was observed between the numerical and experimental results, where yield was initiated in the longitudinal reinforcements at a height of about $40 \mathrm{~cm}$ (twice the column width) from the bottom of the column (Fig. 6a). It is worth noting that the stress of stirrups in this area was lower than the yield stress. Figure 6b shows the stress in the FRP rebars of the specimens. As can be seen, the stress of FRP rebars in the plastic hinge region has reached the ultimate tensile strength, which is consistent with the observation made in the experiments. Figure $6 \mathrm{c}$ shows the stress in the FRP jacket of the specimen. As shown in this figure, the stress produced in the jacket is significantly lower than the tensile strength of the CFRP laminate. Thus, the numerical model exhibits no damage in the jacket, which is also consistent with experimental observations.

Figure 7, where hysteresis curves of real and simulated specimens are portrayed, demonstrates a good agreement between the numerical and experimental results. The numerical and experimental results both point toward the

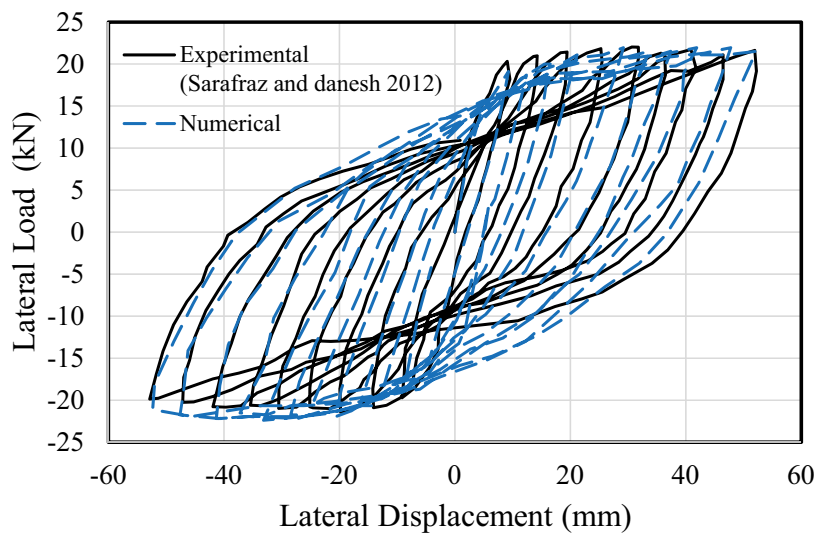

Fig. 7 Comparison of the numerical and experimental load-displacement hysteresis curves

relatively ductile behavior of the specimen. In other words, the numerical model of the FRP jacket has managed to accurately reproduce the effect of confinement of concrete on its strength and ductility. 


\section{Parametric analysis}

A comprehensive parametric study was conducted to better understand the behavior of RC columns strengthened with NSM FRP rebars and FRP jacket. The studied parameters included the axial load applied on the column, confinement of the column base or the entire column, the number of plies of the FRP jacket, the type of jacket fiber, the ratio of NSM reinforcement, and the compressive strength of the concrete. For this purpose, 27 models with specifications listed in Table 2 (including model 2 used for validation) were analyzed numerically under axial and cyclic lateral loads. Geometric dimensions, details of main reinforcement and NSM rebars, and material specifications assumed for these models were similar to the corresponding values in the experiments of Sarafraz and Danesh (2012).

In groups G1, G2, and G3 of Table 2, the effect of axial load on the columns strengthened with different systems was studied. The models of group G1 were strengthened with NSM rebars and FRP jacket applied to the entire height, the models of group G2 were strengthened only with NSM rebars, and the models of group G3 were strengthened with NSM bars and FRP jacket applied to the lower section of the column up to a height of $40 \mathrm{~cm}$ ( $40 \%$ of the overall height). Since numerical results and experimental observations both showed that flexural

Table 2 General specifications of the numerical models

\begin{tabular}{|c|c|c|c|c|c|c|c|c|c|}
\hline Group no. & Model no. & $f_{\mathrm{c}}(\mathrm{Mpa})$ & Axial load $(\mathrm{kN})$ & $\begin{array}{l}\text { Number of } \\
\text { FRP plies }\end{array}$ & $\begin{array}{l}\text { NSM bar } \\
\text { diameter } \\
(\mathrm{mm})\end{array}$ & Jacket fiber & $\begin{array}{l}\text { Groove } \\
\text { width } \\
(\mathrm{mm})\end{array}$ & $\begin{array}{l}\text { Groove } \\
\text { depth } \\
(\mathrm{mm})\end{array}$ & Jacketing region \\
\hline \multirow[t]{5}{*}{ G1 } & 1 & 24.1 & 100 & 2 & 10 & CFRP & 18 & 18 & Entire height \\
\hline & $2^{\mathrm{a}}$ & 24.1 & 200 & 2 & 10 & CFRP & 18 & 18 & Entire height \\
\hline & 3 & 24.1 & 300 & 2 & 10 & CFRP & 18 & 18 & Entire height \\
\hline & 4 & 24.1 & 400 & 2 & 10 & CFRP & 18 & 18 & Entire height \\
\hline & 5 & 24.1 & 500 & 2 & 10 & CFRP & 18 & 18 & Entire height \\
\hline \multirow[t]{5}{*}{ G2 } & 6 & 24.1 & 100 & 0 & 10 & CFRP & 18 & 18 & No jacket \\
\hline & $7^{\mathrm{a}}$ & 24.1 & 200 & 0 & 10 & CFRP & 18 & 18 & No jacket \\
\hline & 8 & 24.1 & 300 & 0 & 10 & CFRP & 18 & 18 & No jacket \\
\hline & 9 & 24.1 & 400 & 0 & 10 & CFRP & 18 & 18 & No jacket \\
\hline & 10 & 24.1 & 500 & 0 & 10 & CFRP & 18 & 18 & No jacket \\
\hline \multirow[t]{5}{*}{ G3 } & 11 & 24.1 & 100 & 2 & 10 & CFRP & 18 & 18 & Column base \\
\hline & 12 & 24.1 & 200 & 2 & 10 & CFRP & 18 & 18 & Column base \\
\hline & 13 & 24.1 & 300 & 2 & 10 & CFRP & 18 & 18 & Column base \\
\hline & 14 & 24.1 & 400 & 2 & 10 & CFRP & 18 & 18 & Column base \\
\hline & 15 & 24.1 & 500 & 2 & 10 & CFRP & 18 & 18 & Column base \\
\hline \multirow[t]{6}{*}{ G4 } & $7^{\mathrm{a}}$ & 24.1 & 200 & 0 & 10 & CFRP & 18 & 18 & No jacket \\
\hline & 16 & 24.1 & 200 & 1 & 10 & CFRP & 18 & 18 & Entire height \\
\hline & $2^{\mathrm{a}}$ & 24.1 & 200 & 2 & 10 & CFRP & 18 & 18 & Entire height \\
\hline & 17 & 24.1 & 200 & 3 & 10 & CFRP & 18 & 18 & Entire height \\
\hline & 18 & 24.1 & 200 & 4 & 10 & CFRP & 18 & 18 & Entire height \\
\hline & 19 & 24.1 & 200 & 5 & 10 & CFRP & 18 & 18 & Entire height \\
\hline \multirow[t]{4}{*}{ G5 } & 20 & 24.1 & 200 & 2 & 6 & CFRP & 12 & 12 & Entire height \\
\hline & $2^{\mathrm{a}}$ & 24.1 & 200 & 2 & 10 & CFRP & 18 & 18 & Entire height \\
\hline & 21 & 24.1 & 200 & 2 & 13 & CFRP & 24 & 24 & Entire height \\
\hline & 22 & 24.1 & 200 & 2 & 16 & CFRP & 30 & 30 & Entire height \\
\hline \multirow[t]{2}{*}{ G6 } & $2^{\mathrm{a}}$ & 24.1 & 200 & 2 & 10 & CFRP & 18 & 18 & Entire height \\
\hline & 23 & 24.1 & 200 & 2 & 10 & GFRP & 18 & 18 & Entire height \\
\hline \multirow[t]{4}{*}{ G7 } & 24 & 20.0 & 200 & 2 & 10 & CFRP & 18 & 18 & Entire height \\
\hline & 25 & 30.0 & 200 & 2 & 10 & CFRP & 18 & 18 & Entire height \\
\hline & 26 & 40.0 & 200 & 2 & 10 & CFRP & 18 & 18 & Entire height \\
\hline & 27 & 50.0 & 200 & 2 & 10 & CFRP & 18 & 18 & Entire height \\
\hline
\end{tabular}

aThe modeling results are subjected to multi-parameter analysis 
hinges form at the lower section of the column, in G3 models, the jacket was applied only to this section. In the numerical model, yielding of longitudinal reinforcements was observed in a length of $40 \mathrm{~cm}$ at the bottom of the column; Thus, this length is considered as the length of the plastic hinge and is selected for FRP jacketing in the models of group G3. Note that since only the half of the column height (from the base to the moment inflection point) was numerically modeled, the length of the FRP jacket in G3 models is equivalent to $20 \%$ of the free height of the prototype column. The models of all three groups were subjected to axial loads of between 100 and $500 \mathrm{kN}$. Since based on Eq. (13) the pure axial load-bearing capacity of the non-strengthened column, $P_{0}$, was approximately $1000 \mathrm{kN}$, the axial loads applied varied between 10 and $50 \%$ of this value.

$P_{0}=0.85 f_{\mathrm{c}}^{\prime}\left(A_{\mathrm{g}}-A_{\mathrm{st}}\right)+f_{\mathrm{y}} A_{\mathrm{st}}$,

where $A_{\mathrm{g}}$ is the gross area of concrete section, $A_{\mathrm{st}}$ is the total area of longitudinal reinforcement, and $f_{\mathrm{y}}$ is the yield strength for reinforcement.
In the models of group G4, the number of plies of the FRP jacket was changed to investigate the effect of this parameter on the column behavior. The purpose of this investigation was to determine the jacket thickness that results in a desirable degree of ductility in the column. In the models of group G5, we changed the diameter of the NSM rebars to examine the effect of the ratio of NSM reinforcement on the column performance. In these models, the groove size was adjusted such that the ratio of rebar diameter to the groove size would remain almost constant. In the models of group G6, we considered two different materials for the jacket, and in the models of group G7, the compressive strength of the concrete was changed in the range of 20-50 MPa. In all models, every parameter other than the one studied was fixed and set equal to the corresponding values in the experimental data.

After the analysis of all models, the hysteresis envelope curves of these models were drawn (Fig. 8). Since the envelope curves were almost symmetric, just the region on the positive loading direction is displayed. To calculate the ductility factors of models, the hysteresis envelope curves were idealized based on ATC-19 (1995) recommendations. In the
(19)

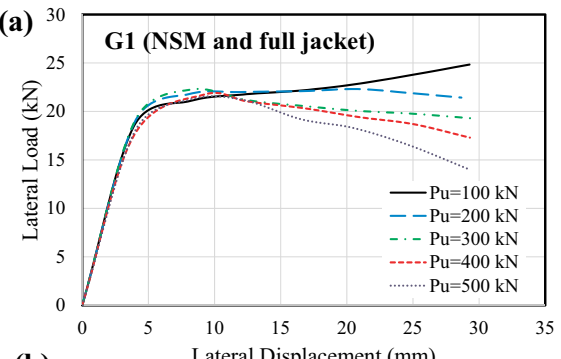

(b)

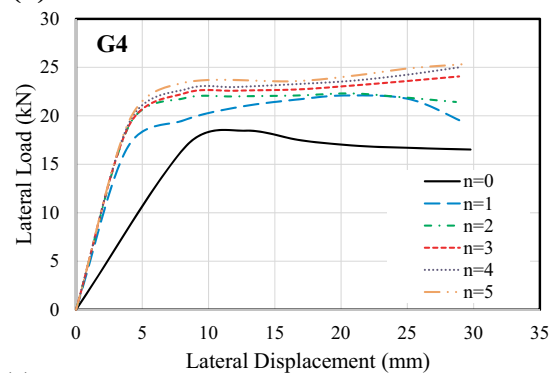

(e)

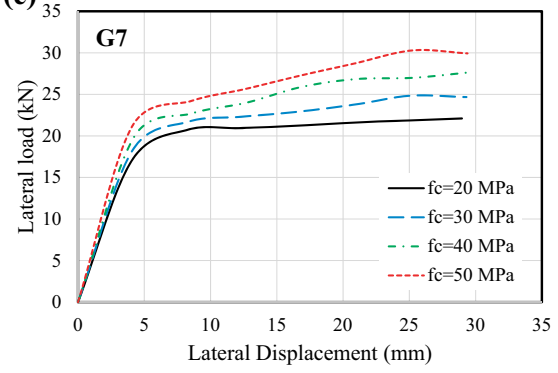

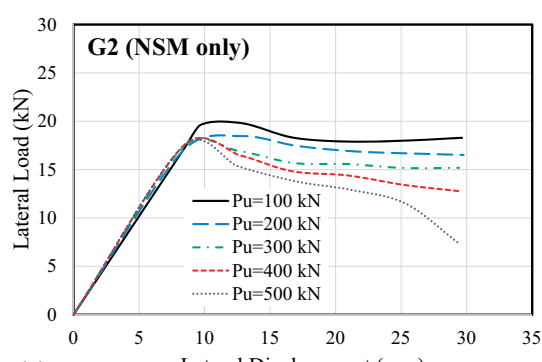

(c)

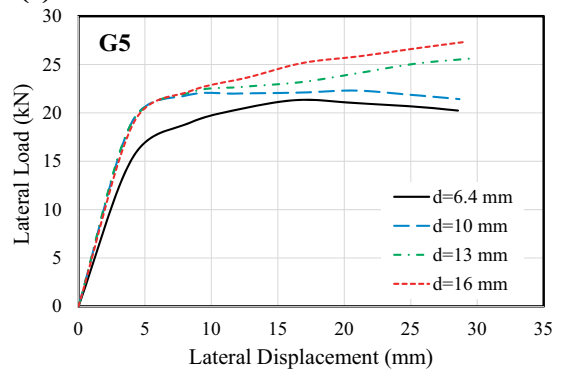

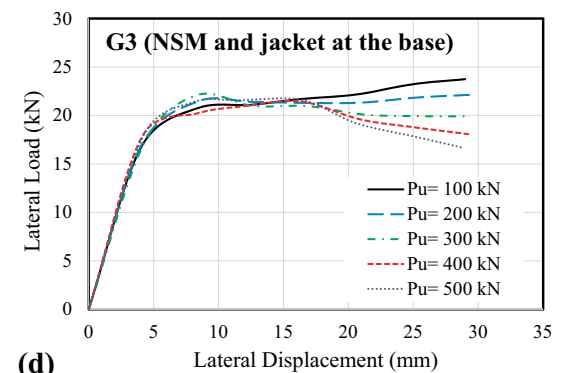

(d)

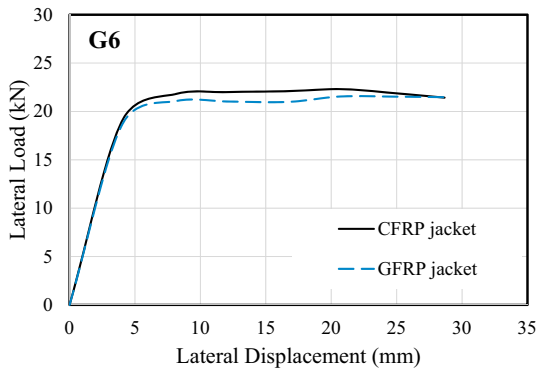

Fig. 8 Hysteresis envelope curves of the numerical models with different design parameters: a axial load (three different strengthening modes); b number of plies of FRP jacket; $\mathbf{c}$ NSM rebar diameter; $\mathbf{d}$ type of jacket fiber; $\mathbf{e}$ compressive strength of the concrete 
following sections, the individual effect of each parameter on the column behavior is discussed.

\section{Axial load}

The axial load is among the most important parameters that influence the behavior of RC columns. An RC column subjected to a combination of axial load and bending moment may experience tensile or compressive failure depending on the magnitude of the applied axial load. Therefore, the effect of this parameter on the behavior of RC columns strengthened with the studied methods requires close examination. The axial load was changed between 10 and $50 \%$ of the axial load-bearing capacity of the non-strengthened column. Figure 8 a shows the hysteresis envelope curves of these models under a lateral load.

Figure 9a shows the lateral strength of the column in three different strengthening modes. According to this figure, since the selected axial loads are larger than the balance point, in all three modes, the lateral strength has an inverse relationship with the applied axial load. According to the results, with the increase in axial load from 100 to $500 \mathrm{kN}$, the lateral strength of G1, G2, and G3 models decreased by $14.5,11.5$, and $8 \%$, respectively. This is because for a column subjected to a combination of axial force and bending moment, as the axial load increases, the column behavior become progressively more dominated by the mechanism of compressive failure, and the application of greater axial load produces higher stresses and strains in the concrete, which end up crushing the material. Figure 9a also shows that the models strengthened with a jacket have on average $25 \%$ greater lateral strength than the models strengthened only with NSM rebars. This is because the confinement of the concrete with FRP jacket increases its ultimate strain and postpones its crushing under compressive stresses. Interestingly, the curves obtained for the models with a jacket applied to the entire height (G1) and with a jacket applied to the bottom section of the column (G3) are very close, particularly for axial loads of greater than $300 \mathrm{kN}$. Since the bending moment peaks at the base of the column and the flexural plastic hinges form in this very same region, the jacket applied to this area makes the most contribution to the strengthening. Thus, there is practically no need to confine the entire height of the column. The results of analyses also indicate that in all models, damage initiates at the base of the column and then spreads upward as the displacement grows.

Figure $9 \mathrm{~b}$ shows the ductility of the models for different axial load values. As can be seen, the highest ductility values belong to the columns with the FRP jacket applied to the entire height, and the lowest ductility values belong to the columns that have the NSM rebars but lack the jacket. For the latter group of columns, there is a marked decrease in the ductility factor with the increase in the axial load. The same observation can also be made in Fig. 8a for these columns. With the increase in lateral displacement, the columns that are subjected to high axial loads exhibit a significant strength reduction. Increasing the axial load raises the axial load-induced strain in the concrete, and adding the bending moment-induced strain to this value causes the unconfined concrete to reach the ultimate strain at lower lateral displacement; thus, the unconfined columns with relatively high axial loads experience brittle failure. In contrast, all columns that had a jacket, for the entire height or only in the bottom section, exhibited a relatively ductile behavior. According to these results, it can be concluded that the sole use of NSM rebars is not a good strengthening solution, especially in the cases with high axial loads, and it is better to also add an FRP jacket to improve the column's ductility. It should also be noted that although fully jacketed models had better ductility than those jacketed at the lower section, the latter specimens were able to maintain an acceptable degree of ductility under increasing axial loads. Therefore, since jacketing the lower section of the column is far more economical and easier than confining its entire height, it can be recommended as the preferable choice for columns under
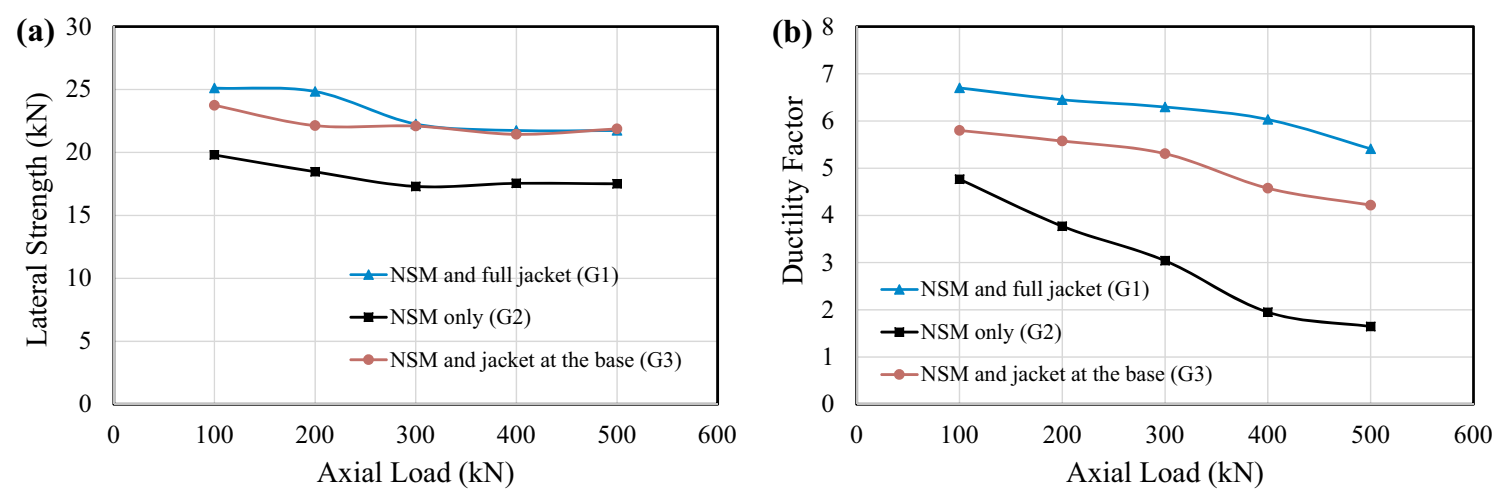

Fig. 9 Effect of the axial load on the hysteresis characteristics of the specimens: a lateral strength; $\mathbf{b}$ ductility 
both axial and lateral loads for providing an acceptable level of safely at a lower cost.

\section{Number of plies of the FRP jacket}

According to the results discussed in the previous section, the addition of FRP jacket improves the ductility and performance of the column. But the optimum number of plies of the jacket, i.e., the number of plies that can provide desirable ductility improvement at a reasonable cost, needs to be determined. Thus, in G4 models, we changed the number of plies of the jacket from zero (no jacket) to five to investigate the effect of this parameter on the results. Figure $8 \mathrm{~b}$ shows the hysteresis envelope curves of these models under the lateral load.

Confining the concrete in an FRP jacket increases its strength and ductility. Based on the recommendation of Lam and Teng (2003a, b), ACI 440.2R-17 (2017) has recommended the use of Eq. (14) for estimating the maximum compressive strength of the confined concrete $f_{\mathrm{cc}}^{\prime}$ and Eq. (15) for estimating the maximum confining pressure $f_{1}$ :

$f_{\mathrm{cc}}^{\prime}=f_{\mathrm{c}}^{\prime}+\psi_{\mathrm{f}} 3.3 \kappa_{\mathrm{a}} f_{1}$,

$f_{1}=\frac{2 E_{\mathrm{f}} n t_{\mathrm{f}} \varepsilon_{\mathrm{fe}}}{D}$.

In these equations, $f_{\mathrm{c}}^{\prime}$ is the unconfined compressive strength of the concrete, $\psi_{\mathrm{f}}=0.95$ is an additional reduction factor, $E_{\mathrm{f}}$ is the elastic modulus of the jacket, $n$ is the number of plies of jacket, and $t_{\mathrm{f}}$ is the nominal thickness of each layer of the jacket. For circular cross sections, $D$ is the diameter. For the rectangular sections, $D$ is given by the following equation:

$D=\sqrt{b^{2}+h^{2}}$,

where $b$ and $h$ are the smaller and larger sides of the rectangle, respectively (Fig. 10).

FRP jackets are more effective in confining circular sections than rectangular ones, since the regular geometry allows the jacket to apply uniform confining pressure on the member. In ACI 440.2R-17 (2017), the effect of the shape of the cross section on the confinement has been formulated based on the shape factors $\kappa_{a}$ and $\kappa_{b}$ :

$\kappa_{a}=\frac{A_{\mathrm{e}}}{A_{\mathrm{c}}}\left(\frac{b}{h}\right)^{2}$,

$\kappa_{b}=\frac{A_{\mathrm{e}}}{A_{\mathrm{c}}}\left(\frac{h}{b}\right)^{0.5}$.

In the above equation, $A_{\mathrm{c}}$ is the cross-sectional area of concrete and $A_{\mathrm{e}}$ is the cross-sectional area of the effectively confined section of the column. As shown in Fig. 10, this section

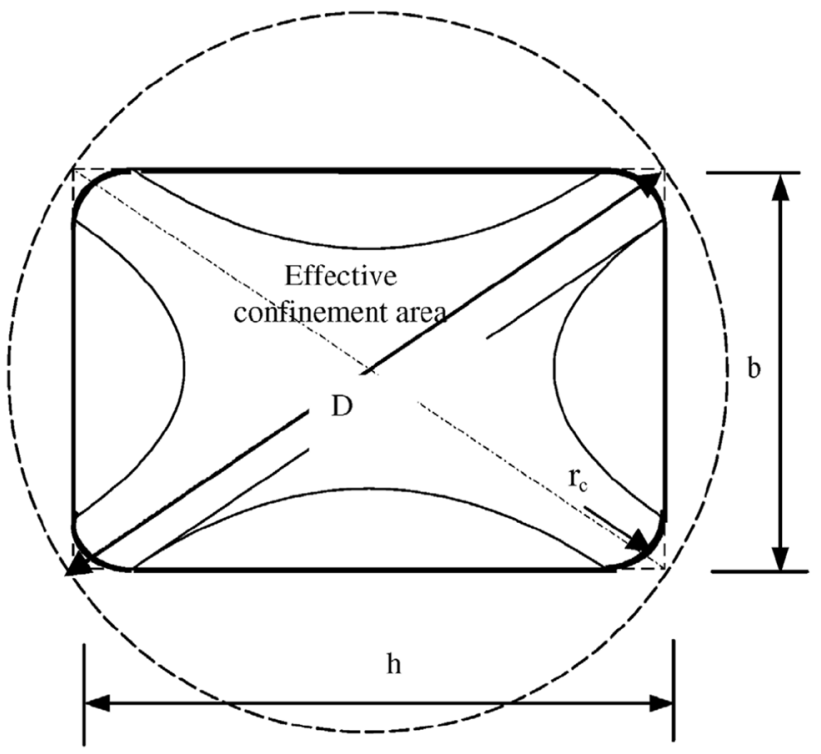

Fig. 10 Equivalent circular cross section (Lam and Teng 2003a, b)

consists of four parabolic regions wherein concrete is perfectly confined. The area of this section is a function of the dimensions of the rectangle ( $b$ and $h$ ), the corner radius $r_{\mathrm{c}}$, the ratio of longitudinal reinforcement $\rho_{\mathrm{g}}$, and the gross area of concrete section $A_{\mathrm{g}}$ :

$\frac{A_{\mathrm{e}}}{A_{\mathrm{c}}}=\frac{1-\frac{\left[\left(\frac{b}{h}\right)\left(h-2 r_{\mathrm{c}}\right)^{2}+\left(\frac{h}{b}\right)\left(b-2 r_{\mathrm{c}}\right)^{2}\right]}{3 A_{\mathrm{g}}}-\rho_{\mathrm{g}}}{1-\rho_{\mathrm{g}}}$.

The effective strain in the FRP member at the moment of failure $\varepsilon_{\mathrm{fe}}$ is given by the following equation:

$\varepsilon_{\mathrm{fe}}=\kappa_{\varepsilon} \varepsilon_{\mathrm{fu}}$,

where $\varepsilon_{\mathrm{fu}}$ is the design rupture strain of the FRP, and $\kappa_{\varepsilon}$ is the FRP strain efficiency factor, which makes sure that the formulation accounts for the premature failure of the jacket. The cause of this premature failure is that the laboratory experiment measures the failure strain under uniaxial stress, whereas in practice the jacket will be subjected to multiaxial stress. Based on the experiments performed on CFRPconfined concrete, Lam and Teng (2003a) have suggested a value of 0.586 for $\kappa_{\varepsilon}$.

The maximum compressive strain of the FRP-confined concrete $\varepsilon_{\text {ccu }}$ can be obtained from Eq. (21) and should be assumed less than 0.01. In the case of using this limit value, the corresponding maximum $f_{\mathrm{cc}}^{\prime}$ value must be obtained from the stress-strain curve of the confined concrete.

$\varepsilon_{\mathrm{ccu}}=\varepsilon_{\mathrm{c}}^{\prime}\left(1.50+12 \kappa_{b} \frac{f_{1}}{f_{\mathrm{c}}^{\prime}}\left(\frac{\varepsilon_{\mathrm{fe}}}{\varepsilon_{\mathrm{c}}^{\prime}}\right)^{0.45}\right)$. 
In the above equation, $\varepsilon_{\mathrm{c}}^{\prime}$ is the maximum unconfined strain corresponding to $f_{\mathrm{c}}^{\prime}$ and can be considered equal to 0.002 .

The above equations were used to calculate the maximum compressive strength of the confined concrete $f_{\mathrm{cc}}^{\prime}$ and the maximum compressive strain in the confined concrete $\varepsilon_{\mathrm{ccu}}$ for the G4 models. The results of these calculations are presented in Table 3.

Figure 11a illustrates the lateral strength of the column strengthened with NSM rebars and different numbers of plies of jacket. According to these results, as the number of plies increases from no layers to five, the lateral strength increases by $37.3 \%$. This strengthening is mainly due to the improvement of concrete strength under confinement. According to Fig. 11a, the specimens with two or more layers of the jacket have almost the same lateral strength. As shown in Table 3, the confined concretes of these specimens also have roughly the same level of compressive strength. At the ultimate limit state of these specimens, the concrete integrity is lost due to excessive cracking and damage; thus, confining the concrete with more layers may not be beneficial in increasing the column lateral strength.

In general, the purpose of the jacket is to improve the ductility of the column. As shown in Fig. 11b, jacketing the column and increasing the number of plies of jacket to two will improve the ductility, but further increase in the number of plies of jacket results in no significant increase in the ductility of the column. In other words, two layers of the jacket are as much effective in providing confinement as are more layers. In practice, using more layers just reduces the stress in the jacket, while the total confining force may remain the same; thus, it does not provide better confinement for the column. According to Table 3, in the model with two layers of jacket, the maximum compressive strain in the confined concrete $\left(\varepsilon_{\mathrm{ccu}}\right)$ is about 0.008 , and in the models with a greater number of layers, $\varepsilon_{\text {ccu }}$ is larger than this value. Concrete with $\varepsilon_{\mathrm{ccu}}$ values of more than 0.008 is expected to undergo excessive cracking and damage and lose its integrity. However, although Eq. (21) gives a $\varepsilon_{\mathrm{ccu}}$ value of greater than 0.008 , the ductility has remained unchanged. Hence, it can be concluded that to achieve a desirable level of ductility with the least number of plies of jacket, we must determine the number of plies that results in $\varepsilon_{\text {ccu }}$ of Eq. (21) becoming equal to 0.008 .

\section{Ratio of NSM reinforcement}

In the models of group G5, we changed the diameter of the NSM rebars embedded on both sides of the confined RC column to investigate the effect of the ratio of NSM reinforcement on the column performance. It should be noted that the groove size was also adjusted such that the ratio of rebar diameter to the groove size would remain almost constant, but other specifications of the models remained as in the corresponding laboratory data. The diameters to be considered for the FRP reinforcement were chosen according to the specifications of commercially available products.
Table 3 Compressive strength and ultimate strain of the concrete confined with different numbers of plies of FRP jacket

\begin{tabular}{lllllll}
\hline Model no. & $n$ & $\frac{A_{\mathrm{e}}}{A_{\mathrm{c}}}$ & $\varepsilon_{\mathrm{fe}}$ & $f_{1}(\mathrm{MPa})$ & $f_{\mathrm{cc}}^{\prime}(\mathrm{MPa})$ & $\varepsilon_{\mathrm{ccu}}$ \\
\hline 16 & 1 & 0.567 & 0.009 & 2.05 & 24.63 & 0.0056 \\
2 & 2 & 0.567 & 0.009 & 4.09 & 28.27 & 0.0082 \\
17 & 3 & 0.567 & 0.009 & 6.14 & 31.05 & 0.0109 \\
18 & 4 & 0.567 & 0.009 & 8.18 & 31.79 & 0.0135 \\
19 & 5 & 0.567 & 0.009 & 10.23 & 32.30 & 0.0161 \\
\hline
\end{tabular}
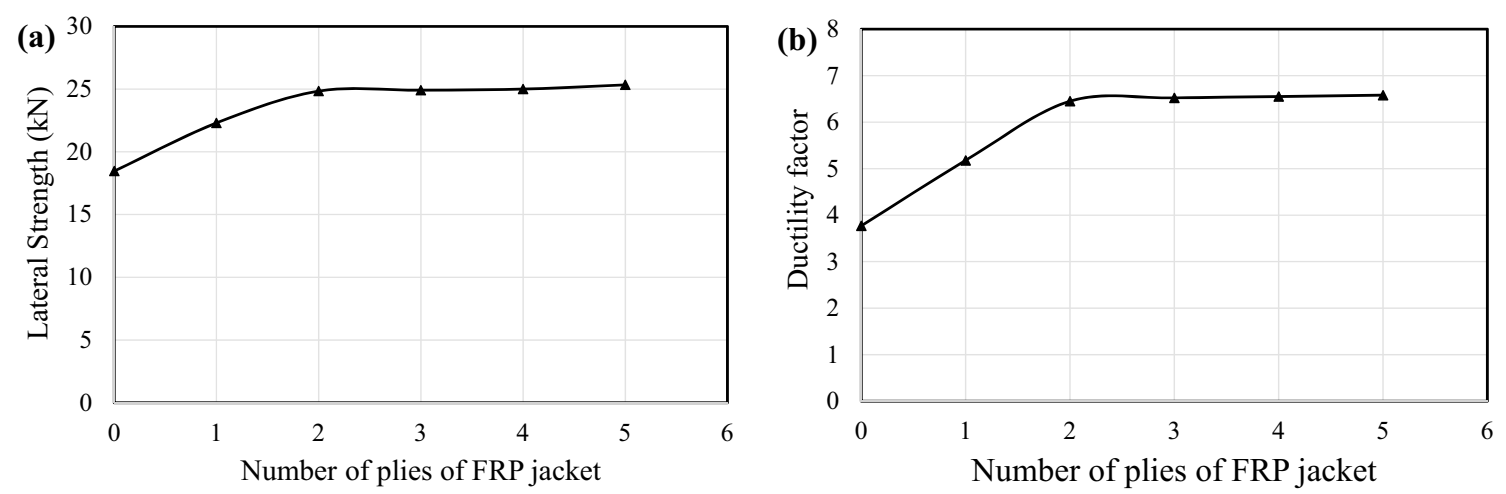

Fig. 11 Effect of the number of plies of jacket on the hysteresis characteristics of the specimens: a lateral strength; $\mathbf{b}$ ductility 
As shown in Table 2, the diameters considered for the NSM rebars were $6.4,10,13$ and $16 \mathrm{~mm}$, which corresponded to NSM reinforcement being $0.16,0.39,0.66$, and $1.00 \%$ of the total cross-sectional area of the column, respectively. Figure $8 \mathrm{c}$ shows the hysteresis envelope curves of these models under the lateral load.

The most important objective of strengthening with NSM rebar is to improve the strength of the column. Increasing the ratio of NSM reinforcement is expected to increase the lateral strength of the column, which depends on the bending strength of the cross section. As shown in Fig. 12a, the increase in the ratio of NSM reinforcement led to a roughly linear increase in the lateral strength of the specimens. More specifically, increasing the area of NSM reinforcement from $0.16 \%$ of the total cross-sectional area to $1 \%$ led to $28 \%$ increase in the lateral strength.

Changing the ratio of NSM reinforcement also changes the ductility factor. As shown in Fig. 12b, increasing the NSM reinforcement ratio resulted in lower ductility factors. In the experiments carried out by Sarafraz and Danesh (2012) too, increasing the ratio of NSM reinforcement led to reduced ductility. Also, in a study conducted by Ding et al. (2013) on eight RC columns strengthened with BFRP NSM rebars combined with BFRP jacket, as the diameter of rebars decreased, ductility and energy dissipation increased. According to the aforementioned results, the choice of diameter of NSM reinforcement is one of the most important decisions in regard to this method.

It should be noted that based on the results of the previous sections, applying FRP jackets can improve the ductility of the member. Thus, decreasing the ductility factor by using NSM reinforcement can be compensated by using FRP jackets. This is one of the advantages of the combined use of NSM FRP rebars and FRP jackets for seismic retrofitting of columns.

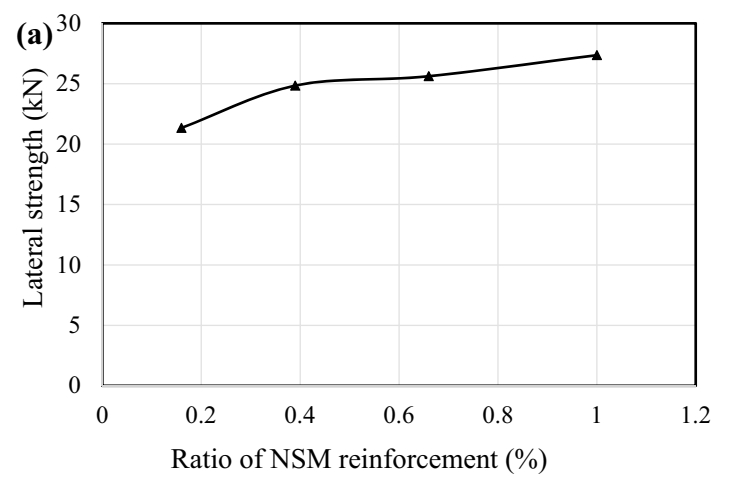

\section{Type of jacket fiber}

To investigate the effect of the type of jacket fiber on the behavior of RC columns, we used the G6 models developed with two types of fiber, CFRP and GFRP, to make a comparison in this respect. The mechanical properties considered for the GFRP fibers are presented in Table 1. Figure 8d shows the hysteresis envelope curves of the columns with these types of FRP jacket.

As shown in Fig. 8d, CFRP and GFRP jacketed models have very similar hysteresis curves. The ductility factors of CFRP and GFRP jacketed models are 6.45 and 6.39, respectively, and are so close to each other. Also, the energy depreciation capacity is only $6 \%$ higher in a CFRP jacketed specimen (Fig. 13). Given the small difference between the results and the low price of glass fibers compared to carbon fibers, when the aim is to increase the column ductility, the use of glass fibers to produce confinement seems to be a more reasonable choice. However, in the practical use of FRP jackets, the effect of other parameters such as durability and fire resistance should also be considered.

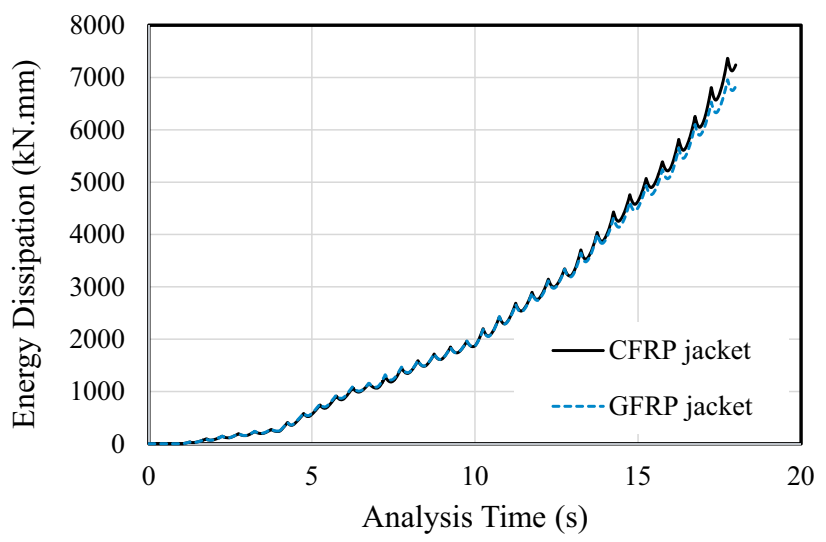

Fig. 13 Energy time histories of the specimens confined with different types of fiber

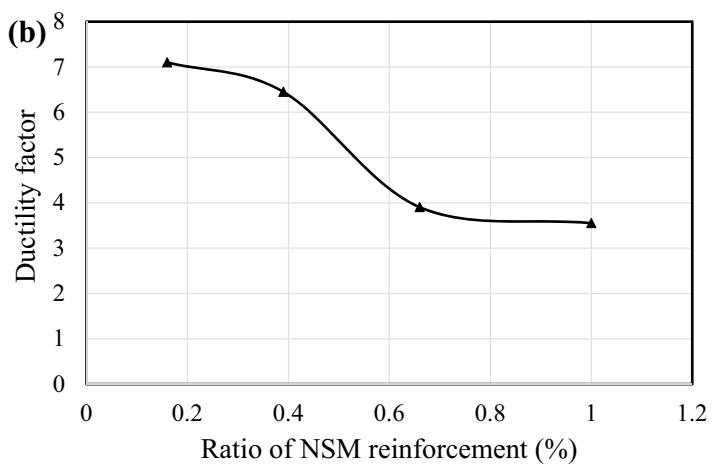

Fig. 12 Effect of the ratio of NSM reinforcement on the hysteresis characteristics of the specimens: a lateral strength; $\mathbf{b}$ ductility 


\section{Compressive strength of concrete}

In the models of group G7, the compressive strength of concrete was changed from 20 to $50 \mathrm{MPa}$ to investigate the resulting effects on the performance of the RC column under axial and lateral loads. Other specifications of the models remained unchanged and were set equal to the corresponding values in the laboratory experiments. The hysteresis envelope curves of these models under the lateral load are plotted in Fig. 8e.

Unsurprisingly, as the compressive strength of the concrete increased, so did the lateral strength of the column. According to Fig. 14a, increasing the compressive strength of concrete from 20 to $50 \mathrm{MPa}$ resulted in approximately $37 \%$ increase in the lateral strength of the model. In general, the compressive strength of concrete has an inverse relationship with its ultimate strain, meaning that high-strength concretes are less ductile than those of lower strength. As shown in Fig. 14b, the increased compressive strength of the concrete led to a significant reduction in the ductility of the column. More specifically, increasing the compressive strength of the concrete from 20 to $50 \mathrm{MPa}$ reduced the ductility by about $50 \%$. The results obtained from G7 models indicate that when using this strengthening approach, a suitable ductility can be achieved with concrete compressive strength values of less than $30 \mathrm{MPa}$.

These results also show that as the compressive strength of the concrete increased, the damage in the member decreased. This is natural because of the ability of highstrength concrete to endure greater compressive stresses. In all cases, the damage initiated at the bottom of the column and then spread upward as the displacement increased. Also, assuming higher compressive strength values for the concrete resulted in the production of greater stresses in the FRP jacket. This is because as the compressive strength of the concrete increases, the model exhibits a greater lateral strength, which results in greater bending moment and thus greater bending moment-induced compressive stress in the model, which, given the tendency of the concrete to expand under compressive stresses, leads to the formation of greater tensile stress in the jacket. Increasing the compressive strength of concrete also increased the level of stress in the adhesive and NSM rebars.

\section{Conclusion}

This research investigated the behavior of RC columns strengthened with NSM FRP bars and FRP jacket. After finite element modeling in the Abaqus software, the numerical models were validated against the experimental data provided by Sarafraz and Danesh (2012). To gain a better understanding of the behavior of RC columns strengthened with this method, the effects of different parameters including the axial load, confinement of the column base or the entire column, the number of plies of jacket, the type of jacket fiber, the ratio of NSM reinforcement, and the compressive strength of the concrete were examined. The most important results obtained from numerical modeling and analyses are as follows:

- In all three studied strengthening methods, the lateral strength had an inverse relationship with the axial load. As we increased the axial load from 10 to $50 \%$ of the axial load capacity of the non-strengthened column, the lateral strengths of the columns strengthened with NSM rebars and complete jacket, the columns strengthened with NSM rebars alone, and the columns strengthened with NSM rebars and jacket applied to the lower section of the column decreased by $14.5 \%, 11.5 \%$, and $8 \%$, respectively.

- In the columns strengthened only with NSM rebars, increasing the axial load resulted in a marked decrease in ductility; but all columns that had a jacket, for the entire height or only in the bottom section, exhibited a relatively ductile behavior. Hence, it can be concluded
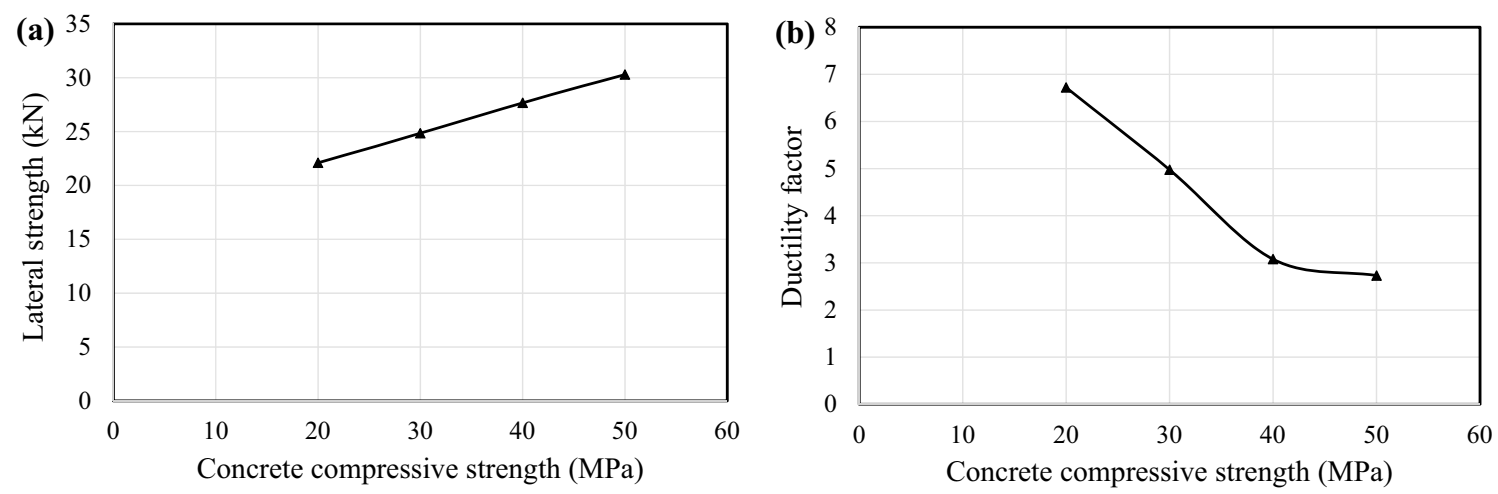

Fig. 14 Effect of the compressive strength of concrete on the hysteresis characteristics of the specimens: a lateral strength; $\mathbf{b}$ ductility 
that the use of NSM rebars alone is not a good strengthening approach, especially under high axial loads, and it is recommended to also apply an FRP jacket to improve the ductility of the column.

- The column strengthened with NSM rebars and jacket applied at the base of the column exhibited acceptable seismic behavior. The maximum lateral strength of these specimens was very close to that of the columns strengthened with NSM rebars and jacket applied to the entire column. Compared to the unconfined columns, the jacketed columns also showed a smaller ductility reduction with the increase in the axial load. Thus, with the economic aspect of discussion taken into consideration, it is recommended to implement the jacket at two ends of the column instead of the entire column.

- Increasing the number of plies of jacket increased the ductility of the column, but after exceeding a certain number of layers, the impact on the ductility became negligible. In other words, there is an optimum number of layers, by which a good degree of concrete confinement can be provided at reasonable cost. In this case, using more layers will not be as much effective because of the expansion of damage and cracking in the concrete. The optimum number of layers is the one that results in the maximum compressive strain in the confined concrete $\left(\varepsilon_{\mathrm{ccu}}\right)$ becoming equal to 0.008 .

- Increasing the ratio of NSM reinforcement from $0.16 \%$ of the total cross-sectional area to $1 \%$ led to approximately $28 \%$ increase in the lateral strength and $50 \%$ decrease in the ductility factor.

- CFRP and GFRP jacketed models had very similar hysteresis characteristics. Thus, considering the lower price of glass fibers than carbon fibers, it is more reasonable to use the jacket made of glass fibers to increase the ductility of the column.

- Increasing the compressive strength of the concrete from 20 to $50 \mathrm{MPa}$ resulted in approximately $37 \%$ increase in the lateral strength and $50 \%$ decrease in the ductility of the model. The results also showed that when using this strengthening approach, a suitable ductility can be achieved with concrete compressive strength values of less than $30 \mathrm{MPa}$.

\section{Compliance with ethical standards}

Conflict of interest The authors declare that they have no conflict of interest.

Open Access This article is distributed under the terms of the Creative Commons Attribution 4.0 International License (http://creat ivecommons.org/licenses/by/4.0/), which permits unrestricted use, distribution, and reproduction in any medium, provided you give appropriate credit to the original author(s) and the source, provide a link to the Creative Commons license, and indicate if changes were made.

\section{References}

ACI 440.2R-17 (2017) Guide for the design and construction of externally bonded FRP systems for strengthening concrete structures. American Concrete Institute, Farmington Hills

ATC-19 (1995) Structural response modification factors. ATC Report 19

Bournas DA, Triantafillou TC (2009) Flexural strengthening of reinforced concrete columns with near-surface-mounted FRP or stainless steel. ACI Struct J 106(4):495

Ding L, Wu G, Yang S, Wu Z (2013) Performance advancement of RC columns by applying basalt FRP composites with NSM and confinement system. J Earthq Tsunami 7(02):1350007. https:// doi.org/10.1142/S1793431113500073

El-Maaddawy T, El-Dieb AS (2011) Near-surface-mounted composite system for repair and strengthening of reinforced concrete columns subjected to axial load and biaxial bending. $\mathbf{J}$ Compos Constr 15(4):602-614. https://doi.org/10.1061/(ASCE) CC. $1943-5614.0000181$

Fahmy MF, Wu Z (2016) Exploratory study of seismic response of deficient lap-splice columns retrofitted with near surfacemounted basalt FRP bars. J Struct Eng 142(6):04016020. https ://doi.org/10.1061/(ASCE)ST.1943-541X.0001462

Hahn HT, Tsai SW (1980) Introduction to composite materials. CRC Press, Boca Raton

Hashin Z (1980) Failure criteria for unidirectional fiber composites. J Appl Mech 47(2):329-334. https://doi.org/10.1115/1.3153664

Jamatia R, Hussain T, Deb A, Bhattacharyya SK (2013) Effect of imperfections in the bond on the strength of FRP wrapped cylindrical concrete columns. Compos B Eng 53:297-307. https:// doi.org/10.1016/j.compositesb.2013.04.056

Jiang SF, Zeng X, Shen S, Xu X (2016) Experimental studies on the seismic behavior of earthquake-damaged circular bridge columns repaired by using combination of near-surface-mounted BFRP bars with external BFRP sheets jacketing. Eng Struct 106:317-331. https://doi.org/10.1016/j.engstruct.2015.10.037

Kabir MZ, Mansouri A (2008) Numerical investigation of the behavior of FRP wrapped RC slender columns under eccentric loading. In: 5th International conference on advanced composite materials in bridges and structures (ACMBS-V), Winnipeg, Manitoba, Canada

Kent DC, Park R (1971) Flexural members with confined concrete. J Struct Div

Lam L, Teng JG (2003a) Design-oriented stress-strain model for FRP-confined concrete. Constr Build Mater 17(6-7):471-489. https://doi.org/10.1016/S0950-0618(03)00045-X

Lam L, Teng JG (2003b) Design-oriented stress-strain model for FRPconfined concrete in rectangular columns. J Reinf Plast Compos 22(13):1149-1186. https://doi.org/10.1177/0731684403035429

Mansouri A, Marefat MS, Khanmohammadi M (2014) Experimental evaluation of seismic performance of low-shear strength masonry infills with openings in reinforced concrete frames with deficient seismic details. Struct Des Tall Spec Build 23(15):1190-1210. https://doi.org/10.1002/tal.1115

Mansouri A, Marefat MS, Khanmohammadi M (2018) Analytical estimation of lateral resistance of low-shear strength masonry infilled reinforced concrete frames with openings. Struct Des Tall Spec Build 27(6):e1452. https://doi.org/10.1002/tal.1452

Moodi Y, Ghorbanzadeh B, Mousavi SR, Esfahani M (2016) The effect of concrete cover on the strengthening of reinforced 
concrete columns with GFRP NSM bars and CFRP confinement system. In: 9th National congress on civil engineering, Mashhad-Iran (in Persian)

Park R, Paulay T (1975) Reinforced concrete structures. Wiley, Hoboken

Perrone M, Barros JA, Aprile A (2009) CFRP-based strengthening technique to increase the flexural and energy dissipation capacities of RC columns. J Compos Constr 13(5):372-383. https://doi. org/10.1061/(ASCE)CC.1943-5614.0000031

Sarafraz ME (2012) Increasing the flexural capacity of reinforced concrete columns by FRP NSM bars. In: Iran's 4th national conference on concrete, Tehran-Iran. (in Persian)

Sarafraz ME, Danesh F (2012) New technique for flexural strengthening of RC columns with NSM FRP bars. Mag Concr Res 64(2):151-161. https://doi.org/10.1680/macr.10.00139

Seifi A, Hosseini A, Marefat MS, Zareian MS (2017) Improving seismic performance of old-type RC frames using NSM technique and FRP jackets. Eng Struct 147:705-723. https://doi.org/10.1016/j. engstruct.2017.06.034
Seifi A, Hosseini A, Marefat MS, Khanmohammadi M (2018) Seismic retrofitting of old-type RC columns with different lap splices by NSM GFRP and steel bars. Struct Des Tall Spec Build. https:// doi.org/10.1002/tal.1413

SIMULIA (2007) ABAQUS analysis and theory manual. Karlsson and Sorensen Inc, Providence

Yao LZ, Wu G (2016) Fiber-element modeling for seismic performance of square RC bridge columns retrofitted with NSM BFRP bars and/or BFRP sheet confinement. J Compos Constr 20(4):04016001. https://doi.org/10.1061/(ASCE)CC.19435614.0000652

Publisher's Note Springer Nature remains neutral with regard to jurisdictional claims in published maps and institutional affiliations. 